\title{
Is Less Actually More? The Usefulness Of Educational Mini-games
}

\author{
Alex Frazer, David Argles, Gary Wills \\ University of Southampton, Southampton, UK \\ \{ajf06r,da,gbw\}@ecs.soton.ac.uk
}

\begin{abstract}
Interest in educational gaming is on the rise once again, and particular interest has started to peak in the area of lightweight educational mini-games. But are these games really as useful as people suggest, or are they simply too shallow to convey sufficient pedagogical meaning? And how do we assess how well these games measure up as educational resources? This paper first generates a "conclusive" list of educational requirements from a structured review of other researchers proposed requirements. It then presents details of the three most interesting educational mini-games taken from an investigation of around 30. Whilst some games were able to offer immersive, curiosity-provoking experiences full of relevant information, many of the games were shallow, formulaic, and lacking in information. Finally, conclusions and future work are proposed, including the packaging of mini-games into compendia to add depth, the use of mini-games in blended learning scenarios, and mechanisms to harvest the relatively simple player interactions to assist learner assessment. These findings aim to help educators make a more informed decision as to whether these games are right for their educational aims.
\end{abstract}

\section{Introduction}

The interest surrounding gaming in education has waxed and waned several times over recent years [1, 3, $10,11]$. One recent peak of interest focuses on the area of mini-games - short, self-contained games, usually based around a single principle, be it ludic or pedagogical. But are these mini-games really that useful in an educational context? Are they deep enough to illustrate the full pedagogical content of a given area? And what set of requirements do we use to evaluate their quality as educational resources?

This paper aims to assess the educational usefulness of mini-games in several steps. First, a structured review of requirements proposed by other researchers is presented, in order to generate a more conclusive overall list of requirements for a good educational resource. Next, an investigation is carried out into a selection of "educational" mini-games, with their qualities compared to the requirements in the list. Finally, the overall usefulness of these games is analysed, with suggestions made for improvements, in order to make them more useful in educational settings. These conclusions should allow instructors to make more informed decisions about the inclusion of minigames in their teaching.

\section{Structured Review of Requirements}

Research claims that a number of requirements for eLearning can be met by the affordances of computer and video gaming. But where did these requirements come from? Different researchers propose different requirements for an e-Learning resource, so which ones should actually be used? This section highlights some of the work regarding the requirements of an e-Learning resource and cross-references them. In doing so, we draw up a more conclusive list of requirements that an educational game must fulfill, and we can begin to assess the usefulness of games in education.

Laurillard's "Conversational Framework" [7] proposes several interactions that must take place for successful learning to occur. Here, the key points to take away from the framework are that:

- instructor-learner interaction should be reciprocal - this allows instructors to keep track of and feed back on learners' progress, and to update their own models and environments to improve the learning experience.

- any theoretical or conceptual model must be exercised in a practical environment - this gives contextual meaning to the model, allowing it to be successfully applied to future practical situations. 
Laurillard also highlights a second conversation -one between the learner's "externally situated" and "internally persistent" selves [6]. It is important for the learner to integrate their conceptualisation of a more specific model with a more generalised, persistent one. In doing this, the learner improves their generalised model to include the more specific, newly acquired context-specific information. Without this internal conversation, new knowledge will only be applicable within a single context, with no potential to apply it to a more general set of scenarios.

Koper and Olivier come up with their own set of requirements, suggesting that learning is becoming more "learner-centred, non-linear and self-directed" [5]. Some of these requirements include:

- integrate learner and instructor activities this improves the articulation between the conceptual models held by the learner and the instructor.

- be customisable to different users' needs - to be as useful as possible, a learning resource should be customisable based on users' existing knowledge and educational requirements. This allows more relevant information to be presented to the user, without boring them with existing knowledge or frustrating them with information that is too complex. This customisation should ideally be automated in real-time, making the learning experience as appropriate as possible at any given time.

- be compatible with different standards - a learning resource should be compatible with compliant environments, allowing it to be reused by multiple users without any further development.

Koper and Olivier also draw attention to Merrill's "first principles of instruction" [8], which suggest learning is promoted when:

- learners are engaged in solving real world.

- existing knowledge is activated as the foundation for new knowledge.

- new knowledge is demonstrated to the learner.

- new knowledge is applied by the learner.

- new knowledge is integrated into the learner's world.

Paras and Bizzocchi [9] highlight yet more requirements, in the form of Norman's "seven basic requirements of a learning environment. These cover areas such as intensity of interaction, provision of welldefined goals, motivation and immersion.

Table 1 - The requirements gathered from previous work, along with the papers from which they were taken

\begin{tabular}{|c|c|c|c|c|c|}
\hline \multirow[t]{2}{*}{ Criterion } & \multirow[t]{2}{*}{ Laurillard } & \multirow[t]{2}{*}{ Koper \& Olivier } & \multirow[t]{2}{*}{ Merrill } & \multicolumn{2}{|c|}{ Paras \& Bizzocchi } \\
\hline & & & & Norman & Keller \\
\hline $\begin{array}{l}\text { Allow conversation between instructor and } \\
\text { learner }\end{array}$ & $\mathrm{X}$ & $\mathrm{X}$ & & $\mathrm{X}$ & \\
\hline Demonstrate new knowledge to the learner & $\mathrm{X}$ & & $\mathrm{X}$ & & \\
\hline $\begin{array}{l}\text { Allow instructor to establish experiential, } \\
\text { explorable environments that are contextually } \\
\text { relevant }\end{array}$ & $\mathrm{X}$ & & & & \\
\hline $\begin{array}{l}\text { Provide opportunity for learners to explore these } \\
\text { worlds }\end{array}$ & $\mathrm{X}$ & $\mathrm{X}$ & $\mathrm{X}$ & $\mathrm{X}$ & \\
\hline $\begin{array}{l}\text { Allow instructors to provide feedback on } \\
\text { learners' actions }\end{array}$ & $\mathrm{X}$ & $\mathrm{X}$ & & $\mathrm{X}$ & \\
\hline $\begin{array}{l}\text { Provide customizable balance between boredom } \\
\text { and frustration }\end{array}$ & & $\mathrm{X}$ & & $\mathrm{X}$ & $\mathrm{X}$ \\
\hline Provide the learner with explicit goals & & & & $\mathrm{X}$ & $\mathrm{X}$ \\
\hline $\begin{array}{l}\text { Allow the learner to integrate new information } \\
\text { with their existing knowledge }\end{array}$ & $\mathrm{X}$ & $\mathrm{X}$ & $\mathrm{X}$ & & \\
\hline Motivate the learner by provoking curiosity & & & & $\mathrm{X}$ & $\mathrm{X}$ \\
\hline $\begin{array}{l}\text { Promote a sense of immersion within the } \\
\text { environment, free from external distractions }\end{array}$ & & & & $\mathrm{X}$ & \\
\hline $\begin{array}{l}\text { Offer rewards when goals are achieved } \\
\text { succes sfully }\end{array}$ & & & & $\mathrm{X}$ & $\mathrm{X}$ \\
\hline Unite a number of learning resources in a single & & $\mathrm{X}$ & & & \\
\hline
\end{tabular}




\begin{tabular}{|l|c|c|c|c|c|}
\hline environment & & & & \\
\hline Support blended and full online learning & & $\mathrm{X}$ & & & \\
\hline $\begin{array}{l}\text { Allow the full pedagogical meaning of data to be } \\
\text { expressed }\end{array}$ & & $\mathrm{X}$ & & & \\
\hline Be compatible with different standards & & $\mathrm{X}$ & & & \\
\hline
\end{tabular}

These requirements reinforce many of those already established, in particular those relating to flow and immersion - by immersing him or herself fully, the learner can absorb information from their own experiences, rather than from instruction. If the immersion is interrupted, the learner's experience will be less effective [2], making it important to use tools and techniques that maintain the immersion.

Paras and Bizzocchi further illustrate the importance of motivation by referring to M. Keller's 'ARCS' method [4], covering strategies in the areas of attention, relevance, confidence and satisfaction.

\section{Analysis}

With all of these requirements in mind, we can now attempt to compile a single list of key requirements for an educational environment. Table 1 shows a potential, more conclusive list, along with the papers from which the requirements were taken. The table suggests that the most important features of an educational resource are the ability for learners to explore contextually relevant environments, learner-instructor conversation, the opportunity for learners to integrate new knowledge with existing models, and the option for instructors to offer feedback on student activities.

Now that we have this list, we can begin to use it to assess the suitability of mini-games as educational resources.

In order to evaluate the different educational qualities offered by mini-games, around 30 games were selected from the BBC Schools website. These games were selected across various topics, including history, science, languages and maths. In addition, games were selected from a range of different types, from simple number puzzles, to intricate reenactments of historic battles. Aside from stating clear goals and providing token rewards (such as a "Well Done!" screen on completion), the simpler word and number puzzles covered almost none of the requirements established in Table 1. However, some of the more complex games were more successful in fulfilling these requirements, with details of three of the more interesting cases presented here.

\subsection{Death in Rome}

This game surrounds the investigation of a mysterious murder in ancient Rome. The game is presented in a classic "point-and-click" adventure style: a detailed, static backdrop with various "hot-spots" scattered around it. These spots relate to objects of interest within the scene, allowing the player to pick up, use or further investigate them with a click of the mouse. This manner of investigation, combined with the murder-

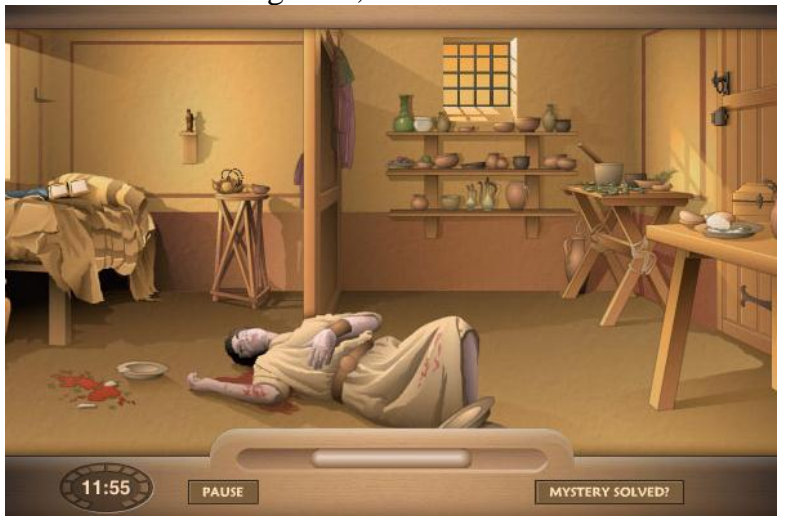

Figure 1 - The murder scene in "Death in Rome" (taken from BBC Schools)

mystery scenario works well in provoking curiosity in the player. The way in which different clues "crossreference" is also an interesting way of helping players to assimilate new knowledge into what they already know. Also, despite its two-dimensional nature, the environment and its contents are still "explorable", with contextually relevant artwork helping players to immerse themselves in the information provided.

The player's goals are set out clearly from the offset: find sufficient clues within a specific time limit, in order to make a confident deduction about the cause of death. With these goals established, the player is able to discover new knowledge within the scene. In addition to the information found by clicking on the objects, the player is able to ask "experts" further questions. These "experts" are either historians, or roman citizens, who provide supplementary information on in-game items at the player's request. This mechanism is useful in two ways. Firstly, it allows the full pedagogical meaning of the objects to be expressed, without overwhelming the player by showing it all at once on the main screen. It also means 
that the player is never forced to read the additional information - they only need only look at it when they need to fill gaps in their knowledge. This provides an interesting balance between boredom and frustration, with help on offer for when it is truly needed.

\subsection{Pyramid Challenge}

Here, the player is given control of the arrangements surrounding the construction of an ancient Egyptian pyramid. Everything from the choice of site, to the materials used, to the types of workforce is left in the player's hands.

On the surface, the game seems as well designed as Death in Rome, with detailed, relevant artwork, and a reasonably well defined long-term goal ("build a pyramid"). However, on actually playing the game, we see that many of the qualities found in Death in Rome are missing from Pyramid Challenge.

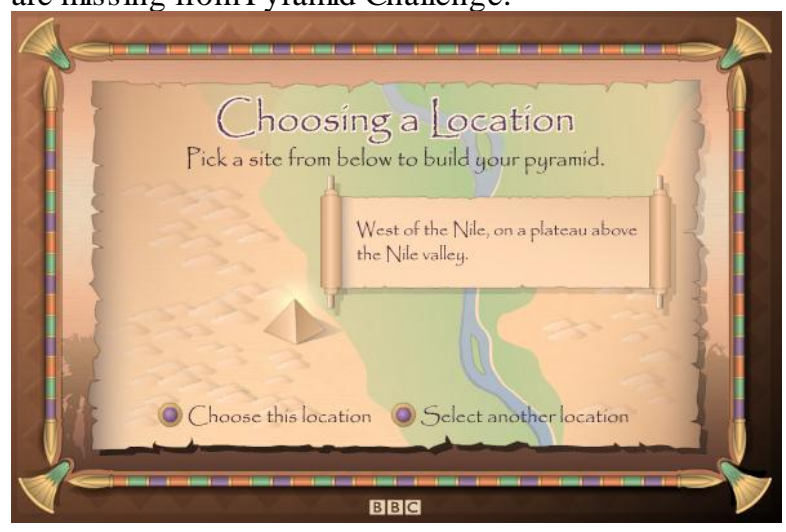

Figure 2 - Choosing a building site in "Pyramid Challenge" (taken from BBC Schools)

The first problem can be seen in the lack of new knowledge presented to the player. Where Death in Rome essentially had one question ("who was the murderer?") and a wealth of new information, Pyramid Challenge asks far more questions without providing anywhere near as much information. Where new information is given, it is often insufficient to allow the player to make informed choices. For example, when selecting a site for pyramid construction, details of the site's location, terrain and convenience are given. However, no clues are given as to how these details relate to the plight of a pyramid builder, making it difficult for the player to contextualise the new information efficiently.

There is also no real incentive for the player to integrate this limited new knowledge into their existing models - for example, once a site has been chosen, it makes no difference to what size of pyramid the player builds, so why should they bother to factor the site location into a persistent mental model?

Curiosity and immersion are also lacking thanks to the game's design. Where the player was able to explore a room in Death in Rome, in this game, the player simply responds to a series of question prompts, as and when they appear. There is no room for exploration, no world in which to be immersed.

A short, arcade-style boat-driving section is included in the game, possibly as motivation ("play the game, have fun driving a boat"), possibly as a reward ("you've completed this much of the game, now have fun driving a boat"). Whilst this may seem like a good idea, the way in which it offers no pedagogical benefits can actually make it act like more of a hindrance. By making such a detached section of the game seem like the "fun part", it infers that the rest of the game (where any actual learning takes place) is the boring part, completely missing the point of using games to benefit education.

\subsection{The Battle of Waterloo}

As the title suggests, this game aims to simulate the actions of the Battle of Waterloo. Viewing the battlefield from an isometric, overhead perspective, the game works in a turn-based fashion with actions controlled by player responses to a series of questions.

The game demonstrates a good amount of new knowledge at the start of the game, with information regarding the army's campaign history and tactics being offered to the player. Whilst rich in its detail, the point at which it is offered could be better - once the game is started, the player cannot go back and look at the information, forcing them to remember it all if they want to succeed.

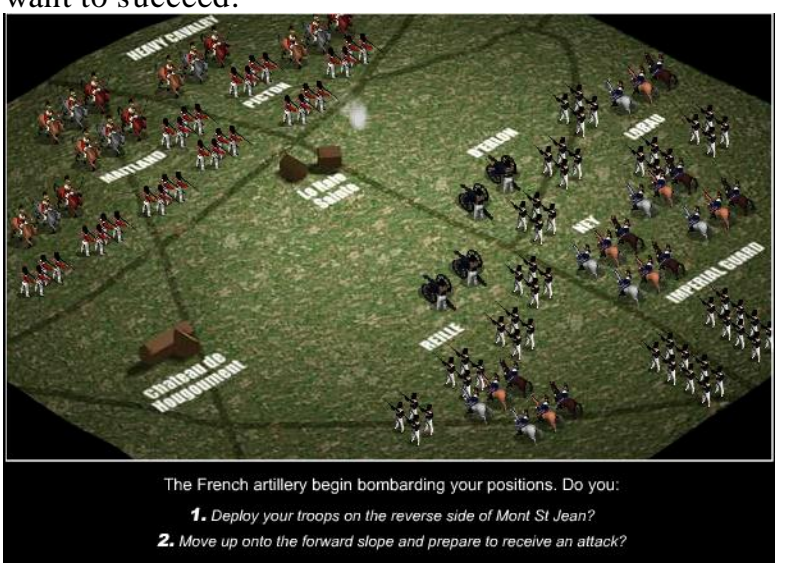

Figure 3 - Troop deployment in "The Battle of Waterloo" (taken from BBC Schools) 
The game mechanic appears poor in its provocation of curiosity, as well as in its balance of difficulty. Because the player is always presented with two tactical choices - one of them right, one of them wrong - they find themselves reluctant to experiment: by trying something different to the correct answer, they are guaranteed to lose. And because their only input into the games outcome is through this choice, there is very little room to balance the game - either the player knows the answer, and they win, or they don't know the answer, and they lose.

However, once the game is completed for the first time, curiosity starts to build. What if the player were to go back and try a different tactical option? What if they were to fight the battle from the other side - and still win? In replaying the game multiple times and in different ways, the player can learn more about how military tactics of the era worked, helping them to contextualise the actual events of the real battle.

\section{Conclusions \& Future Work}

The games described in this paper were selected for discussion because they exemplified many of the qualities and shortcomings of the investigated minigames. Having analysed these features, some useful conclusions and recommendations can be made

With a few exceptions, the games seem to be either too short or too shallow to offer any real sense of immersion. Many of them rely too heavily on question prompts, creating a layer of separation between the player and any immersive in-game content. Death in Rome was selected for discussion as it is a good example of mini-game immersion done well: a single, richly defined room creates a much more immersive experience than an entire vaguely defined empire, kept at arm's length.

None of the mini-games provided any opportunity for conversation or feedback. While perhaps the games are too short for much conversation to be required, assistance with feedback would certainly be possible. Due to the games' simplicity, it should be relatively easy to capture all of the player's significant moves, before collating them in a standard format. This could help instructors assess how well the players interact with the game, allowing them to alter it to better suit their teaching goals.

None of the games really managed to "unite a number of learning resources in a single environment", possibly due to being too short. But if we consider a mini-game to be a resource in its own right, could there perhaps be benefits from uniting a number of different mini-games, incorporating different gameplay mechanics which focus on a single learning topic, into a single compendium? That way, the overarching compendium becomes the game, uniting a number of mini-game resources to better express the pedagogy of a single area.

In addition, by putting multiple mini-games into a series, learners could be helped in their assimilation of new knowledge into their existing mental models. Currently, mini-games are so short that there is often little incentive for learners to contextualise any new knowledge they acquire. But if that knowledge were required in a later "episode" in the series, players would have to reconsider the old knowledge within the newly presented context, reinforcing the integrity of their mental models.

The issues regarding insufficient or untimely provision of information could perhaps be resolved using blended learning. By providing supplementary information with books, lectures and in-class discussion, the mini-games can be kept lightweight, making them more flexible in their development and classroom use.

It can be seen that mini-games have a lot to offer, and some cases can cover almost all of the educational requirements proposed. But in their current state, most games fall short of the mark, in their lack of information, their formulaic gameplay, or their failure to provide a context for their content. By implementing the changes proposed, these mini-games could become the lightweight, flexible gaming solution that educators have been waiting for.

\section{References}

[1] Angelides, M. C., Paul, R. J. (1993). Towards a Framework for Integrating Intelligent Tutoring Systems and Gaming-Simulation. Proc. Winter Simulation Conference, 1993.

[2] Csikszentmihalyi, M. (1997). Flow and Education. In NAMTA Journal 1997, Volume 22, Issue 2.

[3] Gee, J. P. (2004). Learning by Design: Games as Learning Machines. In Interactive Educational Multimedia 2004, Volume 8.

[4] Keller, J. M. (1987). Development and Use of the ARCS Model of Motivational Design. In Journal of Instructional Development 1987, Volume 10, Issue 3. 
[5] Koper, R., Olivier, B. (2004). Representing the Learning Design of Units of Learning. In Educational Technology \& Society 2004, Volume 7, Issue 3.

[6] Laurillard, D. (1999). A Conversational Framework for Individual Learning Applied to the 'Learning Organisation' and the 'Learning Society'. In Systems Research and Behavioral Science 1999, Volume 16, Issue 2.

[7] Laurillard, D. (2002). Rethinking University teaching in the digital age. Available online at http://www.educause.edu/ir/library/pdf/ffp0205s.pdf.

[8] Merrill, M. D. (2002). First Principles of Instruction. In Educational Technology Research and Development 2004, Volume 50, Issue 3.

[9] Paras, B., Bizzocchi, J. (2005). Game, Motivation, and Effective Learning: An Integrated Model for Educational Game Design. Proc. DiGRA 2005 Conference: Changing Views - Worlds in Play.

[10] Pursel, B. K., Bailey, K. D. (2005). Establishing Virtual Learning Worlds. Available online at http://www.personal. psu.edu/staff/b/k/bkp10/vlw_working.pdf.

[11] Squire, K. (2003). Video games in education. In International Journal of Intelligent Simulations and Gaming 2003, Volume 2, Issue 1. 